\title{
Two cases of Paget's disease of scrotum in biological brothers
}

\author{
This article was published in the following Dove Press journal: \\ Therapeutics and Clinical Risk Management \\ 27 May 2015 \\ Number of times this article has been viewed
}

\section{Dapang Rao' \\ Haibo Zhu ${ }^{2}$ \\ Kaiyuan $\mathrm{Yu}^{2}$ \\ Haifeng $\mathrm{Yu}^{2}$ \\ Liping Xie'}

'Department of Urology, First Affiliated Hospital, Medical

College,Zhejiang University, Hangzhou, People's Republic of China;

${ }^{2}$ Department of Urology, Second Affiliated Hospital of Wenzhou

Medical University, Wenzhou, People's

Republic of China
Correspondence: Liping Xie Department of Urology, First Affiliated Hospital of Zhejiang University, Hangzhou 310003, People's Republic of China

Email xielp@zju.edu.cn
Abstract: This article reports two cases of scrotum Paget's disease in two biological brothers who were admitted and treated in our hospital in 2013. They are very rare cases. The present article discusses the potential management of Paget's disease and the importance of long-term follow-up.

Keywords: Paget's disease, case report, follow-up, dissection, metastasis

\section{Introduction}

Paget's disease (PD), also known as eczematoid carcinoma, is generally categorized as mammary Paget's disease (MPD) and extramammary Paget's disease (EMPD). ${ }^{1-6}$ EMPD most frequently occurs in the penis and scrotum as intraepidermal carcinoma of low malignancy ${ }^{1,6-10}$ and is most likely to be misdiagnosed as chronic scrotum eczema, though it is a rare clinical encounter. This article reports two cases of scrotum PD in two biological brothers who were admitted and treated in our hospital in 2013.

\section{Case reports}

The study has been approved by the ethic committee for medical research in Wenzhou Medical College and written informed consent was obtained from both patients.

\section{Case I}

The 56-year-old younger brother was admitted on January 23, 2013 with history of pruritus of the scrotal skin for 6 months and suspicion of PD on pathologic biopsy of the scrotal skin. Physical examination showed eczematoid change of the scrotal skin and a skin defect in the left scrotum measuring approximately $4 \mathrm{~cm} \times 3 \mathrm{~cm}$. No enlarged lymph lode was palpated in the bilateral inguinal regions. Chest X-ray and B-mode ultrasonography were not remarkable. The lesion was resected surgically with a resection margin of approximately $2 \mathrm{~cm}$. Biopsy was performed on bilateral inguinal lymph nodes. Intraoperative frozen section pathology report indicated the diagnosis of PD (Figure 1). No abnormality was detected in bilateral inguinal lymph nodes. Postoperative pathology study confirmed the diagnosis of PD. No tumor was detected in bilateral and bottom cutting edges. No computed tomography (CT) or magnetic resonance imaging (MRI) radiographs were taken before the operation. Following the operation (24 months now), pathological examination and CT/MRI reported no coexisting malignancy.

\section{Case 2}

The 68-year-old elder brother was admitted on January 25, 2013 with history of symptoms similar to those of his younger brother for a year, including pruritus of the 


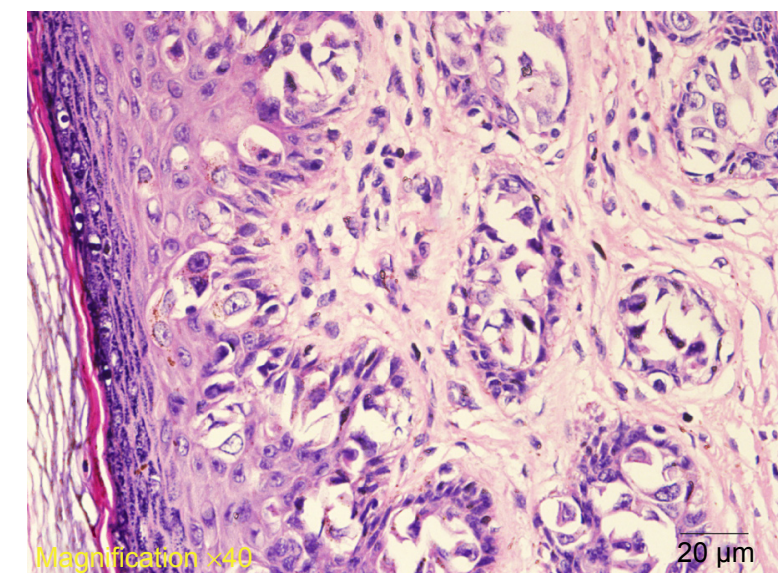

Figure I Pathology study with HE staining of tissue sample from Case I. Abbreviation: HE, hematoxylin-eosin.

scrotal skin associated with enlargement of the left inguinal lymph nodes. Physical examination showed eczematoid change of the scrotal skin and a skin defect in the upper part of the left scrotum and the root of the penis measuring approximately $5 \mathrm{~cm} \times 4 \mathrm{~cm}$. Multiple enlarged lymph nodes were palpable in the left inguinal region, the maximum one measuring approximately $3 \mathrm{~cm} \times 2 \mathrm{~cm}$. They were moderate in consistency and poorly movable. No enlarged lymph node was palpated on the right side. Chest X-ray and B-mode ultrasonography were not remarkable. The lesion was resected surgically with a cutting margin of approximately $3 \mathrm{~cm}$. Biopsy was performed on bilateral inguinal lymph nodes. Intraoperative frozen section pathology report indicated the diagnosis of $\mathrm{PD}$ (Figure 2). Cancer metastasis was detected in two left inguinal lymph nodes, and no abnormality was seen in the right ones. Clearance of the left inguinal lymph nodes was performed, and postoperative pathology study confirmed the diagnosis of scrotum PD and cancer metastasis in the two

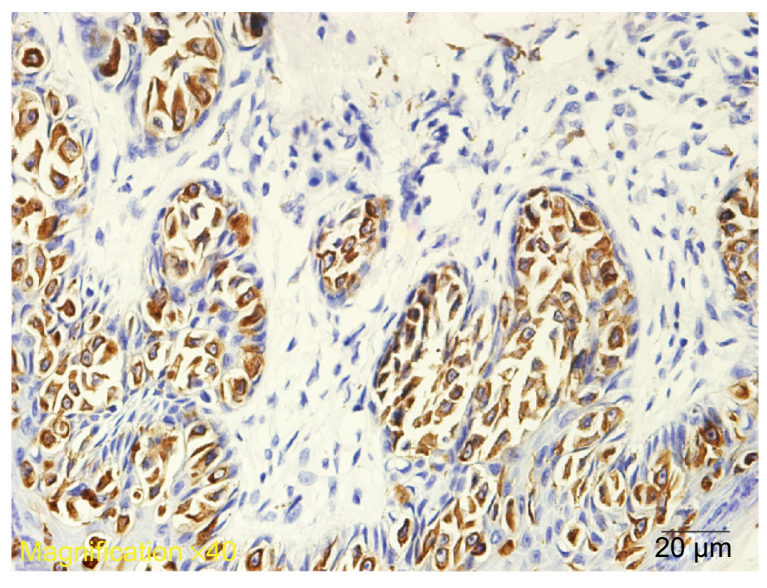

Figure 2 CK7 (immunohistochemistry) of tissue sample from Case 2. left inguinal lymph nodes. Left inguinal lymph node clearance was performed again in 8 weeks, and pathology study confirmed the diagnosis of metastatic PD of scrotum.

\section{Discussion}

PD was first discovered and described in the female breast skin by James Paget in 1874, as noted by Perez et al. ${ }^{11}$ Later, Crocker et al reported the first case of EMPD involving the scrotum and penis, as cited in a study. ${ }^{12}$ Since then, more cases of EMPD involving the clitoris, perianal region, armpit, eyelid, and external auditory canal have been reported. Almost simultaneous occurrence of PD in two biological brothers is rarely reported in the literature. Since Kuehn et a ${ }^{13}$ first reported familial EMPD in 1973, only two articles about familial EMPD have been published in PubMed, ${ }^{2,14}$ suggesting that the disease may be related to familial inheritance, but no related gene has been identified.

Scrotum PD usually progresses slowly. The pathological lesion often grossly presents as eczematoid or chronic inflammatory changes ${ }^{9}$ and is therefore most likely to be misdiagnosed as chronic scrotal eczema, localized neurodermatitis, scrotal dermatitis, or tinea cruris. For this reason, routine biopsy is strongly recommended for eczematoid change of the scrotum that fails to respond to routine treatment for a period of 6-8 weeks to avoid misdiagnosis or maldiagnosis. Large and round Paget cells without intercellular bridges but with rich cytoplasm, light staining, large and irregular nuclei, multiple or giant nucleoli, and mitoschisis are histopathological characteristics of scrotum PD. On the basis of pathological and clinical presentations, the disease is classified by the Rey method into four stages: stage $A_{1}$, the lesion is localized within the scrotum; stage $A_{2}$, the lesion invades adjacent organs such as the penis, testes, and/or spermatic cord without evidence of metastasis to other tissues or organs; stage B, there is inguinal or ilioinguinal lymph node metastasis but the lesion is still visible; stage $\mathrm{C}$, there is ilioinguinal lymph node metastasis and the lesion is nonvisible; and stage $\mathrm{D}$, there is extrailioinguinal metastasis. ${ }^{15,16}$

As the EMPD lesion has no clear boundary and poorly responds to radiochemical therapy, early surgical resection is the treatment of choice, ${ }^{17,18}$ including resection of the fullthickness lesion with a cutting margin $>2 \mathrm{~cm}$. Indications for inguinal lymph node clearance are as follows: 1) Inguinal lymph node biopsy should be performed simultaneously with resection of the scrotal lesion. 2) Inguinal lymph node clearance should be performed in patients with a positive result of biopsy. As most patients are aged, prophylactic lymph node clearance is not advocated. 3) Inguinal lymph 
node clearance should be considered in patients who are still suspected as having the risk of metastasis, although the biopsy result is negative and the inflammatory symptoms have been relieved several weeks after surgical resection. As recurrence is likely to occur, Mohs micrographic surgery with the help of Cytokeratin 7 immunofluorescence staining of frozen sections is recommended because it can significantly reduce the positive rate of the cutting edge and the recurrence rate of PD. ${ }^{19}$ For patients with advanced unresectable PD tumors, local radiotherapy, chemotherapy, or external use of $5 \%$ imiquimod (a new immunomodulator) can be applied to relieve the symptoms. ${ }^{20}$

The prognosis of scrotum PD largely depends on the depth of the lesion invasion, the presence or absence of lymph node metastasis, and the presence or absence of malignancies in adjacent tissues and organs. ${ }^{1,4,5}$ Studies have demonstrated that the prognosis is usually good in patients with stage A scrotum PD without pathological infiltration who have a short course of disease and have received local expanded surgical resection. ${ }^{1,4,11,15}$ In addition, the prognosis is also relatively good in stage A scrotum PD patients with the positive cutting edge as long as they receive local expanded surgical resection immediately after the diagnosis of recurrence is confirmed. Other researchers maintain that long-term follow-up observation is necessary in patients who have received radical surgical resection whether the cutting edge is positive or negative, especially in patients with coexisting malignant tumors. ${ }^{21}$

\section{Disclosure}

The authors report no conflicts of interest in this work.

\section{References}

1. Bagby CM, MacLennan GT. Extramammary Paget's disease of the penis and scrotum. J Urol. 2009;182(6):2908-2909.

2. Demitsu T, Gonda K, Tanita M, et al. Extramammary Paget's disease in two siblings. Br J Dermatol. 1999;141(5):951-953.
3. Juang GD, Lin MY, Hwang TI. Extramammary Paget's disease of the scrotum. JCMA. 2011;74(7):325-328.

4. Ng LG, Yip SK, Tan PH. Extramammary Paget's disease of scrotum. Urology. 2001;58(1):105.

5. Payne WG, Wells KE. Extramammary Paget's disease of the scrotum. Ann Plast Surg. 1994;33(6):669-671.

6. van Randenborgh H, Paul R, Nahrig J, Egelhof P, Hartung R. Extramammary Paget's disease of penis and scrotum. J Urol. 2002; 168(6):2540-2541.

7. Henning JS. Extramammary Paget's disease of the penis and scrotum. J Drugs Dermatol. 2006;5(7):652-654.

8. Isrow D, Oregel KZ, Cortes J, et al. Advanced extramammary Paget's Disease of the groin, penis, and scrotum. Clin Med Insights Oncol. 2014; $8: 87-90$

9. Li B, Ding Q. Extramammary Paget's disease involving the penis, scrotum and the axilla. Australas J Dermatol. 2011;52(1):e18-e20.

10. Park S, Grossfeld GD, McAninch JW, Santucci R. Extramammary Paget's disease of the penis and scrotum: excision, reconstruction and evaluation of occult malignancy. $J$ Urol. 2001;166(6):2112-2116. [discussion 2117].

11. Perez MA, LaRossa DD, Tomaszewski JE. Paget's disease primarily involving the scrotum. Cancer. 1989;63(5):970-975.

12. Anolik R, Liang C, Wang N, Rosenman K, Pomeranz M, Joe E. Extramammary Paget disease. Dermatol Online J. 2008;14(10): 15.

13. Kuehn PG, Tennant R, Brenneman AR. Familial occurrence of extramammary Paget's disease. Cancer. 1973;31(1):145-148.

14. Inoue S, Aki T, Mihara M. Extramammary Paget's disease in siblings. Dermatology. 2000;201(2):178.

15. Parys BT, Hutton JL. Fifteen-year experience of carcinoma of the scrotum. Br J Urol. 1991;68(4):414-417.

16. Ray B, Whitmore WF Jr. Experience with carcinoma of the scrotum. J Urol. 1977;117(6):741-745.

17. Wollina U. Extensive invasive extramammary Paget's disease: surgical treatment. J Cutan Aesthet Surg. 2013;6(1):41-44.

18. Zhang N, Gong K, Zhang X, Yang Y, Na Y. Extramammary Paget's disease of scrotum - report of 25 cases and literature review. Urol Oncol. 2010;28(1):28-33.

19. Petrie MS, Hess S, Benedetto AV. Automated 15-minute cytokeratin 7 immunostaining protocol for extramammary Paget's disease in Mohs micrographic surgery. Dermatol Surg. 2011;37(12):1811-1815.

20. Sendagorta E, Herranz P, Feito M, et al. Successful treatment of three cases of primary extramammary Paget's disease of the vulva with imiquimod - proposal of a therapeutic schedule. J Eur Acad Dermatol Venereol. 2010;24(4):490-492.

21. Jones IS, Crandon A, Sanday K. Paget's disease of the vulva: diagnosis and follow-up key to management; a retrospective study of 50 cases from Queensland. Gynecol Oncol. 2011;122(1):42-44.
Therapeutics and Clinical Risk Management

\section{Publish your work in this journal}

Therapeutics and Clinical Risk Management is an international, peerreviewed journal of clinical therapeutics and risk management, focusing on concise rapid reporting of clinical studies in all therapeutic areas, outcomes, safety, and programs for the effective, safe, and sustained use of medicines. This journal is indexed on PubMed Central, CAS,

\section{Dovepress}

EMBase, Scopus and the Elsevier Bibliographic databases. The manuscript management system is completely online and includes a very quick and fair peer-review system, which is all easy to use. Visit http://www.dovepress.com/testimonials.php to read real quotes from published authors. 